\title{
ACUTE BACTERIAL ENDARTERITIS
}

BY

\section{G. L. ROBINSON AND RONALD HARTLEY}

From the Dreadnought Hospital for Seamen, London

Abnormality of a valve predisposes to bacterial endocarditis, even when mechanical beating action is absent, as in destruction of a cusp by previous rheumatic disease. Yet the formation of vegetations at sites other than valvular endocardium is rare ; and, in spite of the frequency and apparent suitability of aortic ulcers, no report of bacterial endarteritis upon simple atheroma has been found in the list of aortic diseases in the Index Medicus covering the last ten years. However, Sherf and Boyd (1948) say that, in rare cases, acute bacterial endarteritis develops on the basis of syphilitic aortitis or of atheroma. White (1945) points out that the aortic intima may be involved in the endocarditis and that ulceration of the valve, the heart wall, or the wall of the aorta is common in more severe cases. He does not mention an acute endarteritis as occurring in the absence of an endocarditis. Neither do Libman and Friedberg (1941) mention this possibility.

\section{Case Report}

The present case was discovered unexpectedly at necropsy. A male, aged 51, with a twenty-year history of abdominal pain, was admitted to hospital for partial gastrectomy. The operation was performed after transfusion of three pints of blood. A chronic duodenal ulcer, perforating the head of the pancreas, was found. Following operation, fever and cough developed ; X-ray of the chest showed no evidence of lung disease, two days later. The fever settled and the patient departed for convalescence on the thirteenth day.

After a further nine days, he was re-admitted with pyrexia. One week after re-admission the leucocytes had risen to 26,000 , X-ray of the chest was still negative, and a subphrenic abscess was suspected.

Fourteen days after re-admission fluid developed at the right lung base and obscured the movements of the diaphragm. The fluid contained many polymorphonuclear cells; culture was sterile. Penicillin therapy was started. Next day surgical explorations of the subphrenic region and of the abdominal cavity were carried out ; no abnormality was detected. After these operations there was peripheral circulatory collapse. Transfusion of four pints of blood was given but the patient died two days after the second and forty-one days after the first operation. Throughout the illness there was no clinical evidence of embolism.

\section{Post-mortem Findings}

Necropsy was performed the day after death. There was an adherent pericardium, the two layers of which were completely fused by tough, fibrous adhesions separated from the muscle by a layer of fat $2.5 \mathrm{~cm}$. thick. Coronary atheroma was slight to moderate. The right pleural sac contained about one pint of thin pus, the right lung being covered by fibrinous adhesions with some gelatinous pockets defined by old fibrous adhesions. A lung abscess, $5 \mathrm{~cm}$. diameter, was situated about the middle of the posterior half of the right lower lobe and bounded behind by thin pleura 


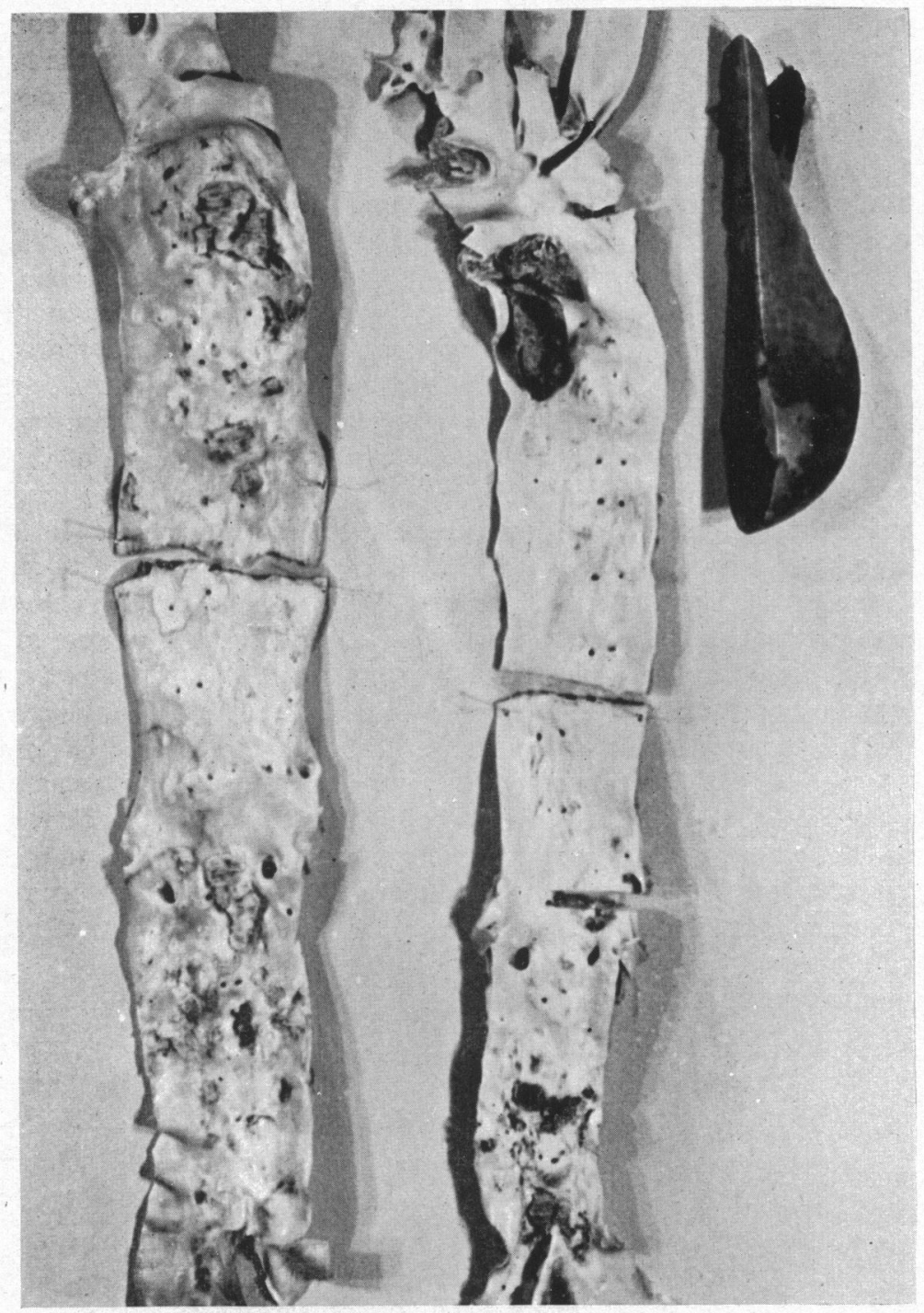

Fig. 1.-(Centre) Aorta of this case. (Left) Aorta from another body showing severe degree of pure atheroma (for comparison). (Right) One of the liver infarcts.

only. The remainder of the wall was composed of firm granulation tissue up to $0.5 \mathrm{~cm}$. thick, and the cavity contained grey fluid pus.

Two large and striking vegetations, resembling those of subacute bacterial endocarditis, were found springing from the aortic intima at a point opposite the origin of the left subclavian artery (Fig. 1). Both were roughly spindle-shaped polyps of blood clot, $3.5 \mathrm{~cm}$. long by up to $2 \mathrm{~cm}$. diameter, lying free in the aortic lumen, except for the attachment of their upper ends to the same atheromatous patch, about $1 \mathrm{~cm}$. diameter, in the aortic wall. Their appearance was that of sausage-meat, fleshy and pink, with some reticulation and a few adherent wisps of black postmortem clot; their consistency was that of a typical friable thrombus, and their surfaces were slightly facetted by being pressed together and against the neighbouring wall. The thoracic aorta showed calcifying atheroma with little ulceration. In the abdominal aorta atheromatous ulcers 
were numerous and several of them were covered by the warty thrombi which commonly build in this situation, while others bore the friable clot of early vegetations similar to the large pair already described.

Numerous pale infarcts, $3 \mathrm{~cm}$. in diameter on the average, with hæmorrhagic borders, were found in the liver (shown in Fig. 1.), and similar smaller infarcts in the cortex of both kidneys. There was infarction of the terminal $100 \mathrm{~cm}$. of the ileum.

Microscopic sections showed a few nests of up to 50 gram-positive cocci in the lining of the lung abscess, the wall of which consisted of chronic pyogenic granulation tissue. The earlier sections through the attachment of one of the polypoid thrombi to the aortic wall failed to reveal any organisms. Many sections were cut and stained before it was found possible to demonstrate organisms. This was finally done by use of Weigert-Gram stain without counter-stain, when they were found in fairly numerous but very small clumps of less than one dozen gram-positive cocci at a time, sometimes in single pairs, round the border (but not in the substance) of the vegetation and also on the free border of the adjoining ulcerated aorta. The opinion reached was that these cocci were streptococci, since the majority were small and tended to be in short chains, although there were a very few clumps of larger more staphylococcal appearance. In one place three bacillary end-to-end forms were noted, such as are seen especially with $S$. viridans. The vegetation itself differed from control sections of the common plateau-clot seen on aortic ulcers in only one other particular, namely, that the fibrin had a pronounced reticular pattern throughout, corresponding to the "fish-scale" macroscopical appearance of the thrombus. In case and controls alike, the whole thrombus was freely peppered by polymorphs.

Sections of the aortic wall at the attachment of the vegetation showed $(a)$ the changes of atheroma in the calcifying stage, and $(b)$ an infiltration of chronic inflammatory cells, mainly in connection with the vasa vasorum, and occurring chiefly in two regions ; the adventitia and the intimal-medial junction. The monocyte was the commonest of these cells, though there were also numbers of plasma cells, lymphocytes and fibroblasts. In a few places, small collections of polymorphs were seen, but always within the lumen of a vessel.

The diagnosis offered on the above findings is that of acute bacterial endarteritis of the thoracic aorta, secondary to lung abscess.

\section{REFERENCES}

Libman, E., and Friedberg, C. K. (1941). Subacute Bacterial Endocarditis. Oxford University Press, London. Sherf, D., and Boyd, L. J. (1948). Cardiovascular Diseases. W. Heinemann, London.

White, P. D. (1945). Heart Disease. Third ed. Macmillan Company, New York. 